\title{
Desafios e perspectivas para a contenção da resistência bacteriana na óptica dos profissionais de saúde
} Health care professionals' view of the challenges and perspectives for containing bacterial resistance

Desafios y perspectivas para contener la resistencia bacteriana en la óptica de los profesionales de salud

Adriana Cristina de Oliveira ${ }^{1}$, Carolina Gonzaga², Rafaela Costa ${ }^{3}$, Quésia Souza Damaceno4, Juliana Ladeira Garbaccio ${ }^{5}$

${ }^{1}$ Enfermeira, Doutora em Enfermagem. Professora Adjunta da Escola de Enfermagem (EE) da Universidade Federal de Minas Gerais (UFMG). Belo Horizonte, MG, Brasil. E-mail: adrianacoliveira@gmail.com.

${ }^{2}$ Acadêmica do curso de graduação em Enfermagem da EE/UFMG. Belo Horizonte, MG, Brasil. E-mail: carolinacgonzaga@hotmail.com.

${ }^{3}$ Acadêmica do curso de graduação em Enfermagem da EE/UFMG. Belo Horizonte, MG, Brasil. E-mail: rafaelacosta03@hotmail.com.

${ }^{4}$ Enfermeira, Mestre em Enfermagem. Discente do Programa de Pós-Graduação em Enfermagem, nível Doutorado, da EE/UFMG. Belo Horizonte, MG, Brasil. E-mail: gdamasceno@yahoo.com.br.

${ }^{5}$ Enfermeira, Mestre em Enfermagem. Discente do Programa de Pós-Graduação em Enfermagem, nível Doutorado, da EE/UFMG. Belo Horizonte, MG, Brasil. E-mail: julianaladeira@pucminas.br.

\section{RESUMO}

O presente estudo objetivou analisar o conhecimento sobre resistência bacteriana, o comportamento, os fatores intervenientes e as perspectivas para controle da disseminação dos micro-organismos resistentes na

ótica dos profissionais de saúde de um hospital universitário. Estudo descritivo realizado por meio de questionário semi-estruturado na Unidade de Terapia Intensiva Adultos e Clínica Médica-cirúrgica. Foram entrevistados 43 profissionais: técnicos de enfermagem, $72,1 \%$; fisioterapeutas, $11,6 \%$; médicos, $9,3 \%$; e enfermeiros, $7,0 \%$. Os micro-organismos resistentes foram referidos por $95,3 \%$ como problema muito importante, apontando o Acinetobacter baumannii multirresistente e o Staphylococcus aureus resistente a meticilina como os mais prevalentes. A ocorrência de micro-organismos resistentes foi atribuída à não adoção de precaução padrão (34,9\%) e aos procedimentos invasivos (21\%); 76,7\% afirmaram perceber a higienização das mãos como muito eficaz; $55,8 \%$ apontaram a categoria médica no foco de atenção para treinamentos. Apesar da percepção da resistência bacteriana pelos profissionais, tal fato não repercute em maior adesão às medidas de controle.

Descritores: Infecção Hospitalar; Farmacorresistência Bacteriana; Pessoal de Saúde; Enfermagem.

\section{ABSTRACT}

The objective of this study was to analyze the knowledge about bacterial resistance, behavior, intervening factors, and perspectives for controlling the dissemination of resistant microorganisms according to the view of the health care professionals of a university hospital. This descriptive study was performed at an Adult Intensive Care Unit and Medical-surgical Clinic using a semi-structured questionnaire. Forty-three workers were interviewed, including (72.1\%) nursing technicians, (11.6\%) physiotherapists, (9.3\%) physicians, $(7.0 \%)$ nurses. The resistant microorganisms were referred by $95.3 \%$ as a very important issue, stating multi-drug resistant Acinetobacter baumannii and methicillin-resistant Staphylococcus aureus as most prevalent. The occurrence of resistant microorganisms was attributed to the non-compliance to the standard precaution (34.9\%) and invasive procedures (21\%); $76.7 \%$ reported perceiving hand washing as very effective; $55.8 \%$ pointed at the medical category when aiming at training. The fact that health care workers perceive bacterial resistance does not reflect in a stronger adherence to control measures.

Descriptors: Cross Infection; Drug Resistance, Bacterial; Health Personnel; Nursing.

\section{RESUMEN}

Se objetivó analizar conocimiento sobre resistencia bacteriana, comportamiento, factores intervinientes y perspectivas para control de la diseminación de organismos resistentes en la óptica de los profesionales de salud de hospital universitario. Estudio descriptivo, realizado mediante cuestionario semiestructurado en Unidad de Terapia Intensiva Adultos y Clínica Médico-Quirúrgica. Fueron entrevistados 43 profesionales, $(72,1 \%)$ técnicos de enfermería, $(11,6 \%)$ fisioterapeutas, $(9,3 \%)$ médicos, $(7,0 \%)$ enfermeros. Los microorganismos resistentes fueron considerados por 95,3\% como problema altamente importante, refiriendo al Acinetobacter baumannii multirresistentes y al Staphylococcus aureus resistente a meticilina como más prevalentes. La ocurrencia de microorganismos resistentes se atribuyó a no adoptar las precauciones estándar (34,9\%) y a los procedimientos invasivos (21\%); 76,7 le otorgaron gran importancia a la higiene de manos; $55,8 \%$ señaló a la planta médica como foco de atención para capacitaciones. A pesar de la percepción profesional de la resistencia bacteriana, el hecho no repercute en mayor adhesión a medidas de control.

Descriptores: Infección Hospitalaria; Farmacorresistencia Bacteriana; Personal de Salud; Enfermería. 


\section{INTRODUÇÃO}

As bactérias resistentes são definidas como aquelas que apresentam resistência a uma ou mais classes de

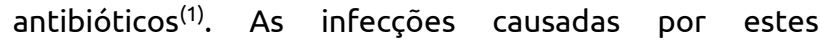
microorganismos apresentam maior preocupação devido ao reduzido arsenal terapêutico disponível para tratamento nestes $\operatorname{casos}^{(1)}$. As infecções relacionadas à assistência a saúde (IRAS), quando associadas a microorganismos multirresistentes, aumentam o tempo de permanência do paciente nos hospitais, os custos e a mortalidade ${ }^{(2)}$. Considerando estes fatos, em 2010, a Organização Mundial de Saúde (OMS) lançou o terceiro desafio global que visa a segurança do paciente pautado na contenção da resistência bacteriana ${ }^{(3)}$.

Neste sentido, a manutenção de um ambiente seguro com menor disseminação de micro-organismos, implica em ações institucionais e em comportamentos individuais adequados dos profissionais de saúde e, de forma sinérgica, culminando de forma positiva em uma melhor adesão da equipe multiprofissional às boas práticas para o controle dos micro-organismos multiresistentes ${ }^{(3-4)}$. Dentre estas destacam-se aquelas preconizadas por agências de saúde nacionais e internacionais como: a adesão dos profissionais de saúde às medidas como higienização das mãos (HM), uso de equipamentos de proteção individual (EPI), a identificação e o estabelecimento de precauções relativas aos pacientes colonizados por micro-organismos multiresistentes ${ }^{(3-4,6-7)}$.

No tocante às instituições, cabe a estas garantir o uso racional de antibimicrobianos que minimiza a pressão seletiva microbiana, apresentar estrutura física adequada que permita isolamento de pacientes, ter localização adequada e número suficiente de pias para $\mathrm{HM}$, fornecer os EPI suficientes e de boa qualidade aos profissionais, possuir uma comissão de controle de infecção atuante no enfrentamento aos micro-organismos resistentes, não apenas na elaboração de normas, mas principalmente voltada para a capacitação profissional.

O comportamento dos profissionais de saúde, referente às precauções, frente aos riscos microbianos tem sido bastante distinto sendo justificado pela falsa percepção de um risco, a subestimação da responsabilidade individual na minimização de um problema. É interessante que nem sempre o comportamento inadequado refere-se à falta de conhecimento acerca dos perigos e formas de transmissão de micro-organismos(8).
Neste contexto considerando a importância da atuação da equipe multiprofissional visando a adoção de boas práticas tornou-se relevante questionar qual é o conhecimento sobre resistência bacteriana, o comportamento e as perspectivas para o controle da disseminação dos micro-organismos resistentes entre profissionais de saúde de um hospital universitário?

A descrição dos desafios e perspectivas dos profissionais de saúde em relação ao controle da resistência bacteriana pode favorecer reflexões sobre as possíveis causas que determinam uma adesão insatisfatória ao uso de EPI determinados para cada tipo de precaução de acordo com as vias de transmissão e para a adesão a higiene das mãos, mesmo após treinamento e preparo para realização de um cuidado seguro.

A abordagem acerca da visão dos profissionais de saúde sobre os aspectos que dificultam o controle das IRAS, associadas aos micro-organismos resistentes, pode contribuir para o conhecimento das condições que prejudicam um manejo mais eficaz das medidas de prevenção da disseminação destes.

A análise das perspectivas dos profissionais que lidam em sua prática assistencial com o aumento progressivo de micro-organismos resistentes associados às infecções, pode favorecer a reflexão sobre as medidas adotadas e adequação destas às condições de trabalho de setores específicos e, principalmente influenciar para a melhoria da adesão dos profissionais a tais medidas.

A identificação de obstáculos percebidos na conciliação da dinâmica de trabalho em saúde concomitante a uma prática segura pode destacar aspectos que merecem maior atenção em treinamentos, elaboração de protocolos e programas que visam o controle das infecções nas instituições de saúde, com direcionamento para a necessidade de desenvolvimento de habilidades cognitivas, psicomotoras e comportamentais que possam "ajudar aos profissionais superar os obstáculos percebidos"(5).

Dessa forma justifica-se a necessidade de analisar, de acordo com as diversas categorias de profissionais de saúde, a visão deles em relação à contenção da resistência bacteriana, tendo em vista a relevância do tema que constitui um problema mundial de saúde pública. Diante disso este estudo teve como objetivo analisar o conhecimento sobre resistência bacteriana, o comportamento, os fatores intervenientes e as perspectivas para o controle da disseminação dos micro- 
organismos resistentes na óptica dos profissionais de saúde de um hospital universitário.

\section{MÉTODOS}

Tratou-se de um estudo descritivo, de janeiro a março de 2012 na Unidade de Terapia Intensiva (UTI) de adultos e na Clínica Médico-cirúrgica de um hospital universitário de Belo Horizonte. A UTI possui 18 leitos e a Clinica Médica 28 leitos, ambos com a seguinte distribuição: quatro enfermarias e duas unidades de isolamento, totalizando 46 leitos.

A população do estudo foram os profissionais de saúde, atuantes nos setores; enfermeiros, técnicos de enfermagem, médicos e fisioterapeutas. Foram critérios para inclusão: profissionais pertencentes à equipe multiprofissional e estarem trabalhando no setor por no mínimo três meses.

Utilizou-se um questionário semi-estruturado para as entrevistas conduzidas pelo entrevistador, um aluno de iniciação cientifica previamente treinado.

O questionário foi dividido em três partes: I características sociodemográficas; II - identificação de comportamento, fatores intervenientes e perspectivas de controle em relação aos micro-organismos multiresistentes; III - conhecimento sobre os microorganismos multiresistentes e as condutas recomendadas no controle da disseminação microbiana. $\mathrm{Na}$ caracterização sociodemográfica incluiram-se as variáveis sexo, idade, tempo de formação, grau de escolaridade, a jornada semanal em horas e o tempo de trabalho no setor. Nas questões sobre comportamento e perspectivas utilizou-se a escala Likert variando de $0-4$, segundo a ordem de prioridade do comportamento referido pelo profissional.

Para o conhecimento foram consideradas corretas as respostas fundamentadas pelos guidelines sobre segurança do paciente, precaução padrão, higienização de mãos e outras referências oficiais das agências e sociedades científicas nacionais e internacionais ${ }^{(3,6-7)}$. Os resultados foram tratados no programa statistical Package for the Social Sciences (SPSS), as variáveis foram analisadas descritivamente.

Os profissionais foram convidados a participar do estudo e o primeiro contato foi por meio verbal, seguido por uma carta de consentimento informado, explicitando os objetivos e a finalidade da pesquisa. A pesquisa foi aprovada pelo Comitê de Ética da UFMG (ETIC
0285.0.203.000-10), fundamentado na Resolução 196/96 do Conselho Nacional de Saúde.

\section{RESULTADOS}

Participaram do estudo 43 profissionais sendo $72,1 \%$ técnicos de enfermagem, 11,6\% fisioterapeutas, 9,3\% médicos, 7,0\% enfermeiros. De acordo com o setor de trabalho 10 (23,3\%) foram da Clinica Médico-cirúrgica e $33(76,7 \%)$ da UTI de adultos. Predominou o sexo feminino $(87,2 \%)$ e a idade variou entre 26 e 51 anos (média 38,5 anos), com maior porcentagem para idades variando entre 26 a 35 anos (49,5\%). Em relação ao tempo de formação na área da saúde prevaleceu o registro entre sete a 15 anos (46,5\%) e quanto à atuação profissional, a maioria tinha entre três meses a cinco anos de experiência no setor. Na avaliação do turno de trabalho 39,5\% dos investigados referiram ter atividades no período diurno seguido por $37,2 \%$ no turno da tarde, 9,3\% no noturno e uma menor parte dos entrevistados realizavam plantões em mais de um turno (7,0\%). Quase metade dos profissionais $(48,8 \%)$ revelou possuir mais de um emprego formal.

Entre os participantes $95,4 \%$ referiram ao problema dos micro-organismos resistentes no seu setor de trabalho como muito importante, 2,3\% importante e 2,3\% pouco importante. Aos entrevistados que responderam muito importante e importante foi pedido que enumerassem por ordem de prioridade a conduta essencial recomendada para auxiliar no controle da disseminação dos micro-organismos e, 37,2\% citaram que "a exigência do uso de EPI como luvas e capote/avental são frequentes para o cuidado aos pacientes", seguido por $32,6 \%$ que referiram que "o uso de precaução padrão tem sido incentivado em treinamentos visando cuidado seguro, independente de representarem um risco à disseminação de tais micro-organismos aos demais pacientes".

Em relação ao conhecimento acerca da resistência bacteriana a maioria dos profissionais relatou a associação entre as IRAS e a resistência bacteriana (Tabela 1). 
Tabela 1: Distribuição da categoria profissional de acordo com o conhecimento adequado sobre resistência bacteriana, Belo Horizonte-MG, 2012.

\begin{tabular}{cccc}
\hline $\begin{array}{c}\text { Categorias profissionais } \\
(\mathbf{n = 4 3 )}\end{array}$ & $\begin{array}{c}\text { Ocorrência da resistência } \\
\text { bacteriana }\end{array}$ & $\begin{array}{c}\text { Associação entre IRAS e } \\
\text { resistência bacteriana }\end{array}$ & $\begin{array}{c}\text { Critérios de } \\
\text { identificação dos MR }\end{array}$ \\
\hline Técnico de enfermagem & $4 / 31(13 \%)$ & $31 / 31(100 \%)$ & $2 / 31(6,4 \%)$ \\
$(31)$ & $0 / 3(0 \%)$ & $3 / 3(100 \%)$ & $0 / 3(0 \%)$ \\
Enfermeiro (3) & $3 / 5(66,6)$ & $5 / 5(100 \%)$ & $0 / 5(0 \%)$ \\
Fisioterapêuta (5) & $4 / 4(100 \%)$ & $3 / 4(75,0 \%)$ & $1 / 4(25,0 \%)$ \\
Médico (4) & $\mathbf{1 1 / 4 3 ( 2 5 , 6 \% )}$ & $\mathbf{4 2 / 4 3 ( \mathbf { 9 7 , 7 } \% )}$ & $\mathbf{3 / 4 3 ( \mathbf { 7 0 } , 0 )}$ \\
\hline Total (43) & &
\end{tabular}

Na análise da principal conduta referida pelos profissionais frente a um paciente com suspeita de colonização/infecção por micro-organismo multirresistente, $83,7 \% \quad(36 / 43)$ dos profissionais responderam que utilizam EPI preconizados para cada situação de risco; 7,0\% (3/43) afirmaram usar luvas estéreis раra qualquer contato com o paciente e $11,6 \%$ (5/43) citaram a HM após realização dos procedimentos junto ao paciente.

Sobre os MR conhecidos pelos respondentes como aqueles mais prevalentes no setor que trabalha no hospital, a maioria $(53,5 \%)$ citou o Acinetobacter baumannii mutirresistentes seguido pelo Staphylococcus aureus resistente à Meticilina (MRSA) (20,9\%).

Ao serem questionados sobre quais fatores poderiam estar associados à disseminação de bactéria multiresistente tendo possivelmente como fonte algum paciente em situação de isolamento no setor onde trabalham, 34,9\% atribuíram ao não uso de precaução padrão para o cuidado aos pacientes, independente do seu diagnóstico, seguido pelo uso de um ou mais procedimentos invasivos pelo paciente $(21,0 \%)$. Sobre as medidas de controle de micro-organismos multirresistentes (MR) adotadas no setor, a HM foi a mais referida pelos profissionais (Gráfico 1).

Gráfico 1: Percentual de adesão às medidas de controle dos micro-organismos resistentes em um hospital Público. Belo Horizonte, MG, 2012.

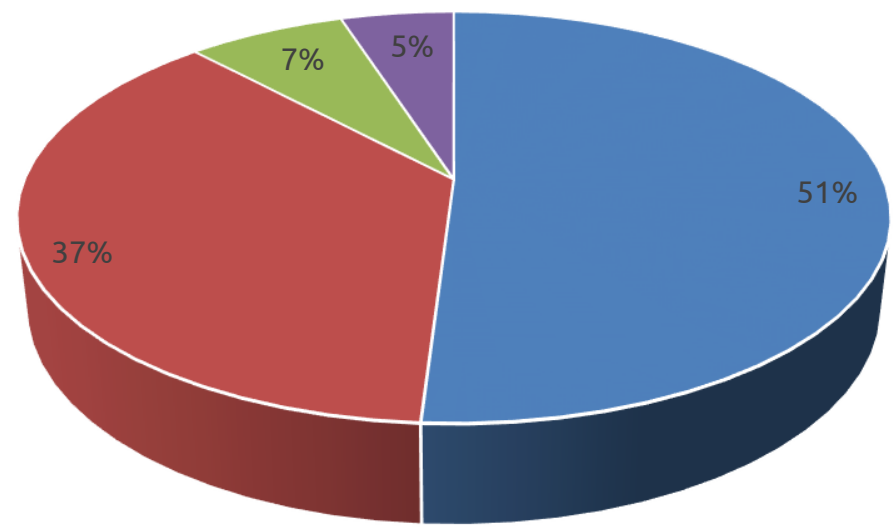

- HM

- Isolamento

- Limpeza do leito/unidade

- Controle de precisão de ATB
Quanto ao conhecimento dos entrevistados sobre o impacto da HM na prevenção das IRAS, 76,7\% afirmaram considerar esta medida como muito eficaz, $16,3 \%$ moderadamente eficaz, 2,3\% eficaz, 2,3\% pouco eficaz e 2,3\% não eficaz.

Entretanto, em relação à eficiência do conjunto de medidas adotadas nos setores para diminuir a disseminação desses micro-organismos $32,6 \%$ dos profissionais as consideraram como muito eficientes, $30,2 \%$ eficientes, $14,1 \%$ moderadamente eficientes, $7,0 \%$ pouco eficientes, $14,0 \%$ ineficientes e $3,2 \%$ não responderam. Os principais motivos para os respondentes considerarem as medidas como ineficientes, pouco ou moderadamente eficientes foram a demora da confirmação laboratorial da identificação de micro-organismo multirresistente $(39,5 \%)$ e a baixa 
adesão da equipe médica às precauções de isolamento representado pelo uso de luvas e aventais/capotes para o atendimento ao paciente $(27,1 \%)$.

$\mathrm{Na}$ análise dos dispositivos de apoio para a $\mathrm{HM}$ a maioria dos entrevistados $(58,1 \%)$ afirmou que havia pias, sabão líquido em dispensadores e álcool gel em quantidade e localização de fácil acesso contribuindo positivamente na prevenção da disseminação de microorganismos. Entre estes $50 \%$ apontaram que os dispensadores de sabão e álcool se encontravam em mau estado de conservação, comprometendo o funcionamento e 31,5\% referiram condições de limpeza ruim dos dispensadores de sabão e de álcool além da ausência em alguns deles do registro de troca destas soluções ou de desinfecção dos recipientes.

Foi questionado aos profissionais de saúde quais estratégias, por ordem de prioridade, deveriam ser adotadas a fim de melhorar o controle da resistência bacteriana nos respectivos setores do hospital onde foi realizada esta pesquisa. Metade dos entrevistados elegeram como prioridade a implementação de uma estratégia que torne as medidas de controle de infecção como algo percebido rotineiramente pela equipe multiprofissional. A capacitação frequente da equipe para as medidas de precaução como a técnica correta de retirada do capote foi referida por $18,6 \%$ dos entrevistados.

Obteve-se entre $69,8 \%$ dos respondentes positividade quanto à participação plena da instituição hospitalar como uma colaboradora na viabilização de condições para a execução das medidas de precaução de contato, 25,6\% afirmaram ser de forma parcial, 2,3\% não sabiam ou não opinaram e $2,3 \%$ disseram que não. Aos que atribuiram restrições à instituição como colaboradora na adesão às precauções de contato $50 \%$ apontaram a disposição dos leitos nas enfermarias desfavorecendo a restrição do acesso ao paciente, $26,7 \%$ a insuficiência de EPI para a manipulação pelos profissionais dos pacientes em isolamento e $20 \%$ pela não adesão por parte dos profissionais no tocante à restrição dos equipamentos para uso exclusivo do paciente em isolamento como o esfigmomanômetro, estetoscópio e termômetros pela escassez deles nos setores do hospital.

A influência de outros profissionais que não aderem aos EPI no comportamento dos entrevistados foi investigada e $76,7 \%$ afirmaram não influenciar, 4,6\% afirmaram que influencia pouco, 18,6\% que influencia moderadamente ou muito.

Segundo os entrevistados, entre as categorias profissionais (enfermeiros, técnicos de enfermagem, fisioterapeutas e médicos) os médicos são os profissionais que mais necessitam de treinamentos em medidas de segurança ou de segurança do paciente (55,8\%). De acordo com 30,2\% dos entrevistados a maior aderência desses profissionais atenuaria a disseminação dos micro-organismos multirresistentes e, 25,6\% afirmaram acreditar que os médicos precisam de capacitação por ignorarem as normas ou não respeitar o isolamento do paciente quanto ao uso de equipamento de precaução para o contato assistencial, dentre outros.

As estratégias para controle da resistência bacteriana implementadas pela Comissão de Controle de Infecção Hospitalar (CCIH) foram registradas como conhecidas por $90,7 \%$ dos profissionais. E, em relação à eficácia da atuação da $\mathrm{CCIH}, 2,3 \%$ a consideram como não efetiva, $7,0 \%$ pouco efetiva, $25,6 \%$ moderadamente efetiva, $46,5 \%$ efetiva e $18,6 \%$ muito efetiva.

No contexto da redução das infecções e um melhor controle da resistência no respectivo setor de trabalho $16,3 \%$ dos profissionais afirmaram perceber as medidas adotadas levar a poucos resultados. E, 53,7\% dos entrevistados consideraram ausente, baixo ou moderado o risco de aquisição de micro-organismo multirresistente no ambiente de trabalho. Em relação ao treinamento recebido sobre medidas de controle de resistência bacteriana nos últimos dois anos $72,1 \%$ confirmaram terem participado. Apenas 23,3\% apresentaram conhecimento adequado sobre os mecanismos que favorecem a seleção de bactérias resistentes aos antimicrobianos e apesar disso $97,7 \%$ dos respondentes afirmaram perceber a ocorrência da infecção hospitalar e resistência bacteriana como eventos associados, sendo que $54,0 \%$ consideraram as complicações dos pacientes causadas por micro-organismos multirresistentes como muito graves e $44,2 \%$ como graves.

\section{DISCUSSÃO}

A predominância de profissionais técnicos, participantes do estudo, esteve relacionada a um maior quantitativo de profissionais da equipe de enfermagem, sendo esta, ainda, em maioria de nível médio conforme observado em outros estudos no Brasil(8-9). 
Apesar de $95 \%$ dos profissionais terem referido a resistência bacteriana como muito importante no setor de trabalho apenas $5 \%$ relataram higienizar as mãos após procedimento com pacientes em suspeita de estarem colonizados por micro-organismos resistentes. Este resultado se mostra coerente com outros estudos, em nível mundial, que reportam uma adesão à HM inferior a $50 \%$ nos casos em que a conduta se faz necessária(8,10-12).

Entretanto, a percepção da resistência bacteriana como problema muito importante no setor de trabalho pelos profissionais pode variar conforme observado em estudos semelhantes ${ }^{(13-14)}$. Em um survey realizado em quatro hospitais na cidade de Pitsburgo (Pensilvânia) e, outra pesquisa em Chicago, ambos nos Estados Unidos, os profissionais de saúde perceberam de maneira similar a resistência bacteriana como um problema predominantemente nacional quando comparado aos respectivos setores de trabalho(14). Em Pitsburgo esta percepção foi de $65,3 \%$ não apenas restrito ao seu setor específico de trabalho, mas como algo de amplitude nacional (94,8\%). Em Chicago a percepção da resistência bacteriana variou significativamente de acordo com o tipo de instituição, constituindo maior preocupação nas instituições de longa permanência (94\%) quando comparado ao hospital municipal (49\%).

A percepção da resistência bacteriana como um evento de muita importância no setor de trabalho foi referida entre profissionais de saúde que participaram de um Workshop com abordagem do controle de infecções e resistência bacteriana, em Atlanta no ano de $2007^{(15)}$. Apesar de não mensuradas, nestes estudos, a associação entre a percepção dos profissionais com variáveis como o tempo de trabalho no setor, frequência de treinamentos em controle de infecções e resistência bacteriana, conhecimento entre outras, possivelmente influenciam na percepção da equipe multiprofissional em relação à resistência bacteriana como um problema local e as implicações relativas ao seu controle.

Neste estudo quando questionados sobre as perspectivas em relação ao controle da resistência bacteriana os profissionais reportaram áreas que podem ser melhoradas, destacando-se o controle de antimicrobianos. Apesar de considerarem que esta, ainda, não constitui uma medida frequentemente adotada. Cabe destacar que o uso criterioso de antimicrobianos constitui importante desafio para o controle da resistência bacteriana ${ }^{(15)}$.
Evidenciou-se também a categoria médica como os profissionais que mais necessitam de treinamento em controle das IRAS e segurança do paciente (60\%), apontados pelos demais profissionais participantes. As outras categorias profissionais consideraram que os médicos conhecem os procedimentos de segurança, mas ainda assim os ignoram, o que pode refletir uma percepção subestimada do impacto da resistência bacteriana no ambiente hospitalar.

Em uma avaliação das ações preventivas da resistência bacteriana estimuladas em campanha direcionada à prevenção desta nas instituições de saúde, lançada em 2002, pelo Center for Disease Control and Prevention (CDC) nos Estados Unidos verificou-se que uma das dificuldades relatadas pela equipe multiprofissional de quatro diferentes hospitais foi a adesão insatisfatória dos médicos às medidas de controle de infecção e a superestimação por estes da necessidade de uso de antimicrobianos ${ }^{(16)}$.

Concernente às medidas seguras na assistência à saúde verifica-se que a maioria das IRAS estão relacionadas às práticas inapropriadas no cuidado ao paciente. Entretanto há consenso de que tais práticas devem ser melhoradas, porém elas implicam na modificação do comportamento dos profissionais de saúde.

Nesse sentido, a educação continuada, a avaliação de resultados das medidas de controle das IRAS nos setores com retorno aos profissionais envolvidos e, o envolvimento dos líderes na realização destas medidas podem favorecer uma melhor adesão dos profissionais de saúde às medidas seguras de assistência aos pacientes ${ }^{(17)}$.

Os principais aspectos relatados pelos profissionais como dificultadores de uma assistência mais segura foram a dificuldade de acesso ao paciente devido a disposição dos leitos nas enfermarias, a insuficiência de EPI para uso em unidades dos pacientes em isolamento, podendo influenciar numa adesão insatisfatória pelos profissionais mesmo quando conscientes da importância destas medidas.

Em um survey realizado em 1998 com profissionais de saúde de hospitais brasileiros, atuantes no controle de infecções, sobre as percepções e atitudes para controle das IRAS e resistência bacteriana uma dificuldade percebida por um terço destes foi a ausência de protocolos para ações relativas ao controle das IRAS. Outro aspecto relevante destacado no survey conduzido 
no Brasil foi a diferença de necessidades relativas aos subsídios para controle das IRAS entre as regiões brasileiras $^{(18)}$.

Merece destaque o achado de que mais da metade dos entrevistados $(53,7 \%)$ consideraram ausente, baixo ou moderado o risco de se contrair micro-organismo multirresistente no ambiente de trabalho, evidenciando um desconhecimento das possíveis fontes e vias de aquisição de patógenos no ambiente hospitalar. Uma maior percepção do risco de aquisição de microorganismos resistentes $(97,6 \%)$ foi observada em estudo descritivo realizado em um hospital geral de Minas Gerais com a equipe de enfermagem. Apesar da percepção do alto risco a mesma equipe apresentou desconhecimento das vias de transmissão, apenas 33,3\% reconheceram a transmissão por contato(19).

Assim, observa-se que o maior risco de aquisição e disseminação de micro-organismos resistentes no ambiente hospitalar podem estar relacionados a vários aspectos como a subestimação do risco, desconhecimento das vias de transmissão e das técnicas adequadas para barreira física, sendo uma das necessidades reportada pelos profissionais para treinamento, a técnica de retirada do capote $(18,6 \%)$.

A percepção de risco e o conhecimento das vias de transmissão de micro-organismos de relevância epidemiológica no ambiente hospitalar constituem aspectos que precisam ser trabalhados em treinamentos periódicos e desde a formação dos profissionais da equipe multidisciplinar ${ }^{(20)}$. Este aspecto foi constatado em estudo sobre crenças e atitudes em relação às medidas de biossegurança entre estudantes de odontologia de uma cidade de São Paulo, no qual se evidenciou a necessidade de aperfeiçoar as estratégias educacionais concernentes à biossegurança para melhorar a adesão e conhecimento entre os futuros profissionais ${ }^{(21)}$.

Estudos sobre a percepção e conhecimento dos profissionais em relação aos desafios para o controle da resistência bacteriana contribuem com informações para a reflexão da dimensão percebida da resistência bacteriana no ambiente hospitalar, favorecendo o planejamento de ações para a prática de um cuidado mais seguro. Entretanto, reconhece-se a limitação quanto ao número de participantes do estudo não permitindo a extrapolação dos resultados obtidos, merecendo que os mesmos possam ser analisados de forma cuidadosa quanto a sua aplicação e, sobretudo incentivando que outros estudos nesta temática sejam realizados envolvendo amostras maiores.

\section{CONCLUSÃO}

Concluiu-se que apesar da percepção da resistência bacteriana pela equipe multiprofissional como muito importante na instituição de estudo, tal fato não repercute em maior adesão às medidas de controle, principalmente, quanto à higienização das mãos. Apesar dos resultados se referirem a informações autoreportadas e não se basear em observação direta das condutas, infere-se ainda assim que possivelmente a percepção e conhecimento não necessariamente refletem na conduta destes profissionais.

Quanto às perspectivas em relação ao controle da resistência bacteriana os profissionais entrevistados destacaram o uso controlado de antimicrobianos como importante medida pelo seu possível impacto na pressão seletiva exercida sobre os micro-organismos patogênicos e, até mesmo, em comensais.

A descrição da percepção e perspectivas dos profissionais da equipe multiprofissional concernente à resistência bacteriana traz importantes informações para reflexões sobre como estes lidam com tal aspecto na sua prática cotidiana em seu setor de trabalho, ressaltando os pontos que precisam ser abordados em treinamentos e elaboração de protocolos. As associações entre percepções, atitudes e conhecimentos constituem tópicos para análise; aspectos não levantados neste estudo, mas de relevância para abordagem em estudos futuros.

Outro ponto que merece atenção é a identificação de obstáculos institucionais que neste estudo, foram pontuados pelos profissionais, comprometendo a adesão às medidas simples e indispensáveis na minimização da disseminação microbiana.

Sugere-se assim maior atenção à realização de treinamentos, reuniões científicas e encontros voltados рага a abordagem da resistência bacteriana em treinamentos envolvendo todos os profissionais. A proposição de abordagens como fóruns de discussão entre os profissionais em relação às dificuldades percebidas e perspectivas relatadas pode favorecer uma maior compreensão do problema, além de subsidiar a elaboração de metas que busquem alcançar a máxima adesão às boas práticas visando um cuidado mais seguro. 


\section{REFERÊNCIAS}

1. Alanis, A. J. Resistance to antibiotics: are we in the postantibiotic era? Arch Med Res. 2005; 36(6):697-705.

2. Smith R, Coast J. The true cost of antimicrobial resistance. BMJ. 2013; 346:1493. [Acesso em: 02 jun 2013] Disponível em: http://www.bmj.com/content/346/bmj.F1493.pdf\%2Bhtml. 3. Organização Mundial de Saúde. World Alliance for patient Safety. World Alliance for Patient Safety FORWARD PROGRAMME 2008-2009. Geneva, 2008. [Acesso em: $04 \mathrm{dez}$ 2011]. Disponível em:

http://www.who.int/patientsafety/information centre/reports/ Alliance_Forward Programme_2008.pdf

4. Agnew C, Flin R, Mearns K. Patient safety climate and worker safety behaviours in acute hospitals in Scotland. Journal of Safety Research. 2013; 45(6):95-101;

http://www.sciencedirect.com/science/article/pii/S0022437513 $\underline{000091 .}$.

5. Brevidelli MM, Cianciarullo TI. Fatores psicossociais e organizacionais na adesão às precauções-padrão. Rev Saúde Pública. 2009; 43(6): 1-10.

6. Agência Nacional de Vigilância Sanitária. Segurança do paciente: higienização das mãos. Brasília (DF): Agência Nacional de Vigilância Sanitária; 2009 [Acesso em: 15 jan 2012] Disponível em:

http://bvsms.saude.gov.br/bvs/publicacoes/seguranca_paciente servicos saude higienizacao maos.pdf

7. Siegel JD, Rhinehart E, Jackson M, Chiarello L; Health Care Infection Control

Practices Advisory Committee. Guideline for Isolation

Precautions: Preventing Transmission of Infectious Agents in

Healthcare Settings. Am J Infect Control. 2007 Dec; 35(10 Suppl

2): S65-164.

8. Oliveira AC, Cardoso CS, Mascarenhas D. Conhecimento e comportamento dos profissionais de um centro de terapia Intensiva em relação à adoção das precauções de contato. Rev Latino-am Enfermagem 2009;17(5). [Acesso em: 12 fev 2012]. Disponível em:

http://www.scielo.br/pdf/reeusp/v44n1/a23v44n1.pdf 9. Perroca MG, Jericó MC, Calil ASG. Composição da equipe de enfermagem em Unidades de Terapia Intensiva. Acta Paul Enferm 2011;24(2):199-205.

10. Organização Mundial de Saúde. World Alliance for patient Safety. Who guidelines on hand hygiene in health care. First global patient safety challenge clean care is safer care. Geneva, 2009. [Acesso em: 12 nov 2009]. Disponível em:

http://whalibdoc.who.int/publications/2009/9789241597906 e ng.pdf.

11. Henderson DK. Managing methycillin-resitant staphylococci: A paradigm for preventing nosocomial transmission resistant organism. Am J Infect Control 2006; 34:36-54.

12. Warye KL, Murphy DM. AJIC presidents'message - Targeting zero health care-associated infections. Am J Infect Control 2008;36(10):683-4.

13. Giblin BT, Sinkowitz-Cochran RL, Harris PL, Jacobs S, Liberatore K, Palfreyman MA, Harrison El, Cardo DM. Clinicians' Perceptions of the Problem of Antimicrobial Resistance in Health Care. Arch Intern Med. 2004;164(15):1662-8.

14. Wester CW, Durairaj L, Evans AT, Schwartz DN, Husain S, Martinez E, MD. Antibiotic Resistance - A Survey of Physician Perceptions. Arch Intern Med. 2002;162:2210-6.

15. Abbo L, Sinkowitz-Cochran R, Smith L, Ariza-Heredia E, Gómez-Marín O, Srinivasan A, Hooton TM. Faculty and resident physicians' attitudes, perceptions, and knowledge about antimicrobial use and resistance. Infect Control Hosp Epidemiol. 2011; 32(7):714-8.

16. Siegel, JD; Rhinehart, E; Jackson, M; Chiarello, L. Healthcare infection control practices advisory committee. Management of multidrug-resistant organisms in healthy care settings,
2006.United states, 2006. [Acesso em: 07 abr. 2010]. Disponível em:

http://www.cdc.gov/ncidod/dhap/pdf/ar/mdroGuideline2006.p df.

17. Brinsley K, Sinkowitz-Cochran R, Cardo D, and the CDC Campaign to Prevent Antimicrobial Resistance Team. An assessment of issues surrounding implementation of the Campaign to Prevent Antimicrobial Resistance in Healthcare Settings. Am J Infect Control. 2005;33:402-9.

18. Guerra CM, Ramos MP, Penna VZ, Goto MJ, Santi LQ, Stempliuk VA, Sallas J, Medeiros EAS. Perceptions and attitudes of the professional staff concerning infection surveillance and control programs in Brazilian hospitals. Am J Infect Control. 2010;38:59-62.

19. Moura JP, Gir E. Nursing staff knowledge of multi-resistant bacterial infections. Acta Paul Enferm 2007; 20(3):351-6. 20. Oliveira AC, Silva RS. Desafios do cuidar em saúde frente à resistência bacteriana: uma revisão. Rev. Eletr. Enf. [Internet]. 2008:10(1):189-197. [acesso em: 12 ago 2012]. Disponivel em: http://www.fen.ufg.br/revista/v10/n1/v10n1a17.htm.

21. Pinelli C, Garcia PPNS, Campos JADB, Dotta EAV. Biossegurança e Odontologia: crenças e atitudes de graduandos sobre o controle da infecção cruzada. Saúde Soc. 2011;20(2):448-61.

Artigo recebido em 26/08/2012. Aprovado para publicação em 29/05/2013. Artigo publicado em 30/09/2013. 